\title{
Studies on Sustained Release Ofloxacin Polymeric Topical films for Wound Healing
}

\section{Dr. Pradnya Palekar - Shanbhag*, Miss. Tejal Gawade\#, Mr. Ansari Imtiyaz Ejaz\$, Mr. Jayesh Jain”, Mr. Pravin Bangar\#, Mr. Ronak Jain\#}

*HOD \& Professor, Department of Pharmaceutics, Oriental College of Pharmacy, Sanpada, Navi Mumbai, Affiliated to University of Mumbai, India.

\$HOD \& Assistant Professor, Department of Pharmacology, Oriental College of Pharmacy, Sanpada, Navi Mumbai, Affiliated to University of Mumbai, India.

${ }^{\#}$ M. Pharm. research students, Department of Pharmaceutics, Oriental College of Pharmacy, Sanpada, Navi Mumbai 400705. Affiliated to University of Mumbai, India.

*Corresponding author's E-mail: drpradnyaps@gmail.com

Received: 21-06-2020; Revised: 18-08-2020; Accepted: 26-08-2020.

DOI: 10.47583/ijpsrr.2020.v64i01.020

\section{ABSTRACT}

Wound healing is a biological process related to growth and tissue regeneration. It includes five stages called overlapping stages with complex biochemical and cellular processes. Topical polymeric films have been used widely for tissue repair of wounds. The primary objective of the research study was to prepare Ofloxacin topical polymeric films with antimicrobial as well as wound healing properties. Ofloxacin is a fluoroquinolone antimicrobial agent which has broad range of activity against gram positive as well as gram negative micro-organisms. Ofloxacin films prepared using chitosan, PVA and carbopol showed effective wound healing activity for prolonged time. These films were characterized using various parameters such as thickness, swelling index, in vitro drug release, in vitro diffusion study, etc. The antimicrobial efficiency of the films was evaluated against S. aureus and E. coli. The wound healing activity of the films was determined by testing on female Sprague Dawley rats. The results revealed that Ofloxacin polymeric films can serve as a superior potential topical drug delivery system for wound healing.

Keywords: Ofloxacin, wound healing, chitosan, topical, polymeric film, antimicrobial.

\section{INTRODUCTION}

Wound dressing material should be maintaining a moist environment and electrolyte balance at the wound interface, allowing gaseous exchange, removing excess of exudates ${ }^{1}$ possessing antimicrobial properties for infection control, and promoting faster wound healing. ${ }^{2}$ Use of polymeric films has been very wide in tissue repair and wound management. Polymeric films provide large surface area of application; remains adhered at the affected area or wound for prolonged period of time along with faster absorption of exudates from the wound. ${ }^{3}$

Due to infection, wound healing process is highly impaired and this has led to the need for drug incorporated films. These are formulated using antibiotics in the polymers used for making the films. ${ }^{4,5}$ Such drug embedded films create a strong barrier to harmful microorganisms once placed on the affected wound. This prevents enhancement of further secondary infections during wound healing and thus improves healing mechanism. Hence drug incorporation into such films finds advantages so as to prevent augmentation of secondary infections on the wound for faster and better wound healing. In addition, there is one more advantage that the drug remains unchanged in the polymer matrix and therefore, its pharmacological properties after the release remains identical as that of the native drug. Chitosan is a linear copolymer of $\beta(1 \rightarrow 4)$ linked 2 - acetamido-2-deoxy- $\beta$-D-glucopyranose and 2-amino-2deoxy- $\beta$-D-glycopyranose. This is obtained by alkaline deacetylation of chitin, the main component of the exoskeleton of crustaceans, such as shrimps and insects. Chitosan is soluble in dilute aqueous acetic, lactic, malic, formic and succinic acids. Chitosan is helpful in wound healing as it stimulates hemostatis and accelerates tissue regeneration. Chitosan has marked antimicrobial effects due to destabilization of the outer membrane of Gramnegative bacteria and permeabilization of the microbial plasma membrane.

Chitosan is biocompatible. It is metabolized by human enzymes, such as lysozyme, thus, it is biodegradable. The monomeric unit in chitosan, $\mathrm{N}$-acetyl glucosamine is similar to that occurs in hyaluronic acid, an extracellular macromolecule that is important in wound repair. ${ }^{6}$ Chitosan is a good candidate for topical administration of antimicrobials. ${ }^{7}$ As chitosan has low mechanical strength, it necessitates the need for use of water-soluble, nontoxic polymers such as cellulose derivative poly vinyl alcohol (PVA) to be blended with it. PVA has good mechanical properties, excellent chemical resistance, biodegradability and film forming ability. ${ }^{8}$ Carbopol is a hydrophilic, mucoadhesive, biocompatible crosslinked polymer of polyacrylic acid. It is used in biomaterials as wound dressings, topical and transdermal preparations. ${ }^{9}$ Ofloxacin polymeric films were prepared using 
combination of chitosan with PVA as well as chitosan with carbopol using solvent casting method.

\section{MATERIALS AND METHODS}

Ofloxacin was purchased from Yarrow Chem Products, Mumbai. Chitosan, PVA, glycerin were procured from HiMedia Chemical Pvt. Ltd., Mumbai. Carbopol 940 was obtained as a gift sample from Lubrizol.

\section{Preparation of Ofloxacin Polymeric Films:}

Solution of chitosan was prepared by dissolving it in $2 \%$ lactic acid. Polymeric films were prepared using combination of polymers. Aqueous solutions of PVA and carbopol were prepared separately. Solutions of chitosan and PVA were mixed in appropriate proportions using magnetic stirrer. In a similar manner, solutions of chitosan and carbopol were mixed and stirred using magnetic stirrer. Glycerin was added to this mixture serving the purpose of plasticizer and penetration enhancer. Ofloxacin was added to the above mixtures in the required amounts. The mixture was poured into petridishes and kept in the oven at $50{ }^{\circ} \mathrm{C}$ for around $48 \mathrm{~h}$. Composition of Ofloxacin polymeric film formulations F1 $-F 7$ is shown in Table 1.

Table 1: Composition of Ofloxacin Polymeric Films

\begin{tabular}{|c|c|c|c|c|c|c|c|}
\hline \multirow{2}{*}{ Ingredients } & \multicolumn{7}{|c|}{ Formulations } \\
\hline & F1 & F2 & F3 & F4 & F5 & F6 & F7 \\
\hline Ofloxacin (g) & 0.064 & 0.064 & 0.064 & 0.064 & 0.064 & 0.064 & 0.064 \\
\hline Chitosan (\%) & 1.0 & 1.25 & 1.5 & 1.5 & 1.5 & 1.5 & 1.5 \\
\hline PVA (\%) & - & - & - & 2 & 4 & - & - \\
\hline Carbopol 940 (\%) & - & - & - & - & - & - & 0.5 \\
\hline Carbopol 934 (\%) & - & - & - & - & - & 0.5 & - \\
\hline Glycerin (\%) & 100 & 100 & 100 & 100 & 100 & 100 & 100 \\
\hline $2 \%$ Lactic acid (ml) & 50 & 50 & 50 & 25 & 25 & 25 & 25 \\
\hline Distilled water (ml) & - & - & - & 25 & 25 & 25 & 25 \\
\hline
\end{tabular}

\section{Characterization of Ofloxacin Polymeric Films}

\section{Thickness}

Thickness of the films was determined using digital Vernier Caliper. Films were analyzed for thickness at four different places and recorded. The mean thickness was calculated.

\section{Folding Endurance}

It was determined by repeatedly folding one film at the same place till it breaks or folded up to 200 times manually. The number of times the film could be folded at the same place without breaking gives the value of folding endurance.

\section{Swelling index}

The films of size $1 \times 1 \mathrm{~cm}^{2}$ were immersed in phosphate buffer saline $\left(\mathrm{pH} \mathrm{7.4)}\right.$ at $37{ }^{\circ} \mathrm{C}$ for $24 \mathrm{~h}$ to determine water uptake property. Initially the dry weight of the films was noted as $W_{0}$. The wet swollen films were taken out at specific time intervals and the excess water was removed carefully using filter paper and weighed immediately as $W_{1}$. The $\%$ swelling was calculated using the below formula.

$$
\text { \% Swelling }\left(\mathrm{W}_{0}-\mathrm{W}_{1}\right) / \mathrm{W}_{1} * 100
$$

\section{Drug Content}

Drug content was determined by dissolving the films of area $1 \mathrm{~cm}^{2}$ in $15 \mathrm{ml}$ of phosphate buffer $\mathrm{pH} 7.4$ using magnetic stirrer. An aliquot of $0.1 \mathrm{ml}$ was withdrawn and diluted to $10 \mathrm{ml}$ with phosphate buffer $\mathrm{pH}$ 7.4. Drug content was quantified by measuring the absorbance at $\lambda$ $291 \mathrm{~nm}$ using UV/ Vis Spectrophotometer.

\section{In vitro drug release}

Release of Ofloxacin from the films was evaluated by USP Type 5 Apparatus (Paddle over disk) in $500 \mathrm{ml}$ phosphate buffer solution $\left(\mathrm{pH} \mathrm{7.4)}\right.$ at $37 \pm 0.5{ }^{\circ} \mathrm{C}$. The rotary paddles were adjusted at $50 \mathrm{rpm}$. At regular intervals aliquots were removed and diluted to appropriate amount and measured by UV/ Vis spectrophotometer at $\lambda 291 \mathrm{~nm}$.

\section{Antimicrobial study}

The antibacterial activity of the placebo as well as those loaded with Ofloxacin was examined by using bacterial strains of $S$. aureus (Gram positive bacteria) and E. coli (Gram negative bacteria) using disc diffusion method. Film of area $1 \mathrm{~cm}^{2}$ was placed in petridish on Agar seeded with bacterial cell suspension adjusted to McFarland standards. The petridishes were incubated for $24 \mathrm{~h}$ at 37 ${ }^{0} \mathrm{C}$. The tests were performed in triplicate. Zone of inhibition was measured after $24 \mathrm{~h}$.

\section{Animal Study}

Wound healing efficacy of the films was assessed by 'Wound Healing - Excision Model'10 in Sprague Dawley rats after the approval from Institutional Animal Ethics Committee of Oriental College of Pharmacy. 15 Female Sprague Dawley rats weighing 180-220g were divided into 5 groups. Each group comprised of 3 rats. The hair on the dorsal part was removed. The animals were anesthetized 
using local anesthetic. Following this a circular open excision type wound of diameter $1 \mathrm{~cm}$ was created. The open excision type wound of $175 \mathrm{~mm}^{2}$ was covered with sterile gauze in Group I which is the control group. In Group II, III and IV the respective developed film formulation for animals was applied to the wound everyday and covered with sterile gauze held in place with the adhesive tape. In case of Group V drug ointment was applied everyday and covered with sterile cotton gauze held in place with an adhesive tape. The groups are mentioned in Table 2. The change in wound size over a period of 2 weeks observed and recorded. At the $7^{\text {th }}$ and $14^{\text {th }}$ day, each wound size was measured and wound contraction calculated. Wound contracture will be expressed as percentage reduction in wound area of originally excised wound.

Wound contracture $=$ (wound area on day 1-wound area on day 14) *100 wound area on day 1

Table 2: Treatment Groups for Animal Study

\begin{tabular}{|c|c|c|}
\hline Sr. No. & Treatment Groups & No. of animals \\
\hline 1 & Group I (sterile gauze) & 3 \\
\hline 2 & Group II (Blank polymeric film) & 3 \\
\hline 3 & Group III - F5 & 3 \\
\hline 4 & Group IV - F7 & 3 \\
\hline 5 & $\begin{array}{c}\text { Group V (Ofloxacin ointment) } \\
\text { Marketed preparation }\end{array}$ & 3 \\
\hline
\end{tabular}

\section{RESULTS AND DISCUSSION}

\section{Thickness}

The thickness of the films increased depending on the volume and concentration of chitosan. F5 films showed mean thickness of $0.30 \pm 0.031 \mathrm{~mm}$. F7 films showed mean thickness of $0.20 \pm 0.003 \mathrm{~mm}$. The thickness of the films was uniform throughout.

\section{Folding Endurance}

Formulations F5 and F7 did not show any cracks even after folding for more than 200 times. The values are shown in the Table 3.

Table 3: Weight and Folding Endurance of Optimized Formulations

\begin{tabular}{c|c|c|}
$\begin{array}{c}\text { Optimized } \\
\text { Formulations }\end{array}$ & Weight (g) & $\begin{array}{c}\text { Folding } \\
\text { Endurance }\end{array}$ \\
\hline F5 & $0.110 \pm 0.028$ & $200 \pm 5.7$ \\
\hline F7 & $0.05 \pm 0.02$ & $200 \pm 5.5$ \\
\hline
\end{tabular}

\section{Swelling index}

Swelling behaviour of films was analyzed at different time intervals. Chitosan films showed highest swelling percent followed by Chitosan - PVA blend films. Chitosan carbopol films showed less swelling as compared to the other films. The swelling behaviour is graphically shown in Fig. 1. It was seen that swelling was maximum in $1 \mathrm{~h}$ for all films. After an hour, it was observed that the swelling reduced gradually and after $20 \mathrm{~h}$ there was no further decrease. Films with combinations of chitosan with PVA and chitosan with carbopol 940 showed less swelling compared to those with chitosan alone, due to interlinking of the polymers.

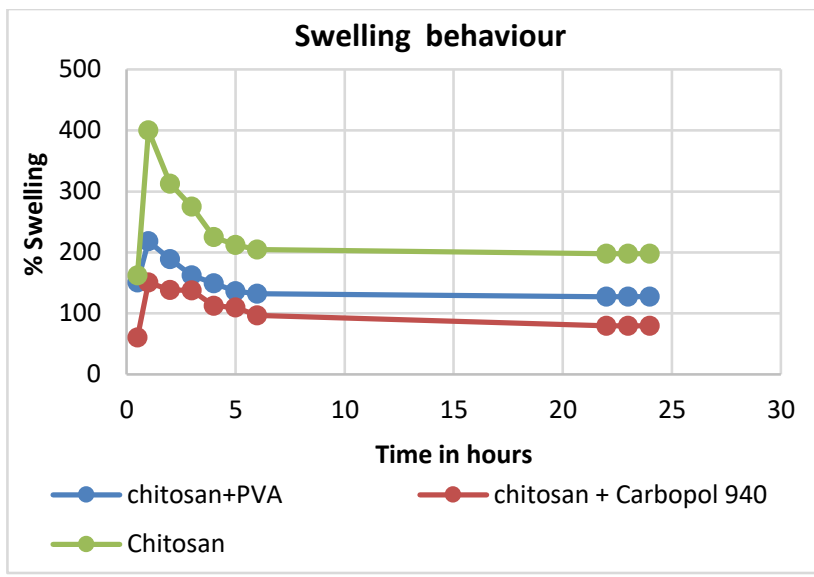

Figure 1: Swelling behaviour of Ofloxacin polymeric films F3 ( $1.5 \%$ chitosan), F5 ( $1.5 \%$ chitosan with $4 \%$ PVA) and F7 ( $1.5 \%$ chitosan with $0.5 \%$ carbopol 940$)$

\section{Drug content}

The drug content of films was determined using UV/ Vis Spectrophotometric analysis for Ofloxacin at $\lambda 291 \mathrm{~nm}$. The drug content is given in Table 4.

\section{In vitro drug release}

The drug release pattern of films F5 and F7 was almost similar. Initially there was burst release of drug but then the release slowed down and continued overnight. The release pattern is shown in the Fig. 2. The dissolution parameter values $\mathrm{t} 50$ and $\mathrm{t} 90 \%$ for films F5 and F7 are shown in Table 4.

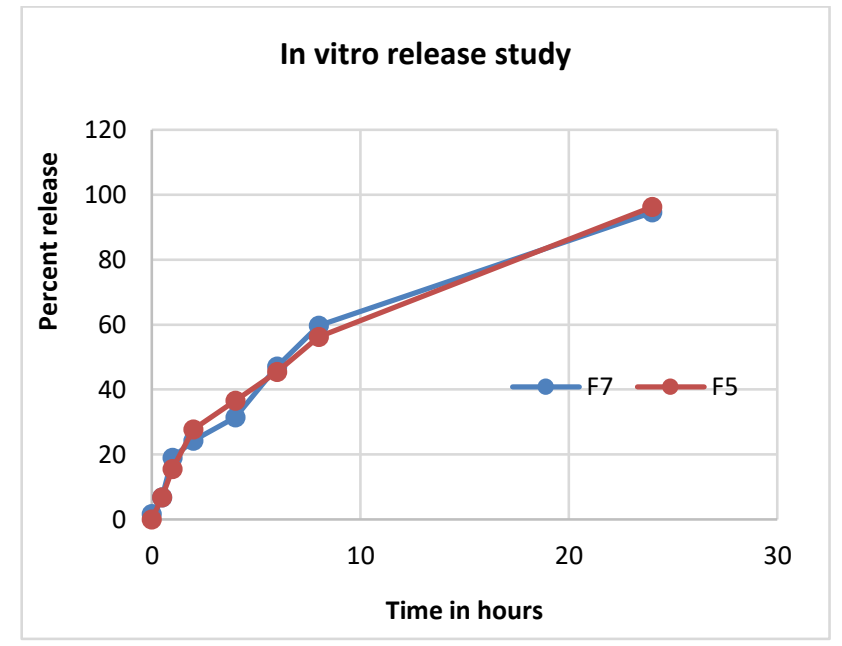

Figure 2: In vitro release pattern of optimised formulations F5 and F7 
Table 4: Drug Content and Dissolution Parameters of Optimized Formulations

\begin{tabular}{|c|c|c|c|}
\hline \multirow{2}{*}{ Optimized Formulations } & Drug Content (\%) & \multicolumn{2}{|c|}{ In vitro Dissolution arameters (h) } \\
\hline F5 & $97 \pm 0.985$ & $t_{50 \%}$ & $t_{90 \%}$ \\
\hline F7 & $98 \pm 0.951$ & 4.48 & 15 \\
\hline
\end{tabular}

\section{Antimicrobial study}

Antimicrobial activity of placebo as well as films loaded with Ofloxacin was evaluated against $E$. coli and S. aureus that are the most common causative micro organisms present in the wound. The objective was to ensure that the film exhibits the desired antibacterial activity. The films loaded with drug showed antimicrobial activity with zone of inhibition as shown in Table. 5.

Table 5: Zone of Inhibition by Optimized Formulations

\begin{tabular}{|c|c|c|}
\hline \multirow{2}{*}{ Optimized Formulations } & \multicolumn{2}{|c|}{ Diameter of zone of inhibition $(\mathbf{m m})$} \\
\cline { 2 - 3 } & S. aureus & E. coli \\
\hline F5 & $9.5 \pm 1.7$ & $10.29 \pm 1.4$ \\
\hline F7 & $11.43 \pm 0.8$ & $12.96 \pm 0.5$ \\
\hline
\end{tabular}

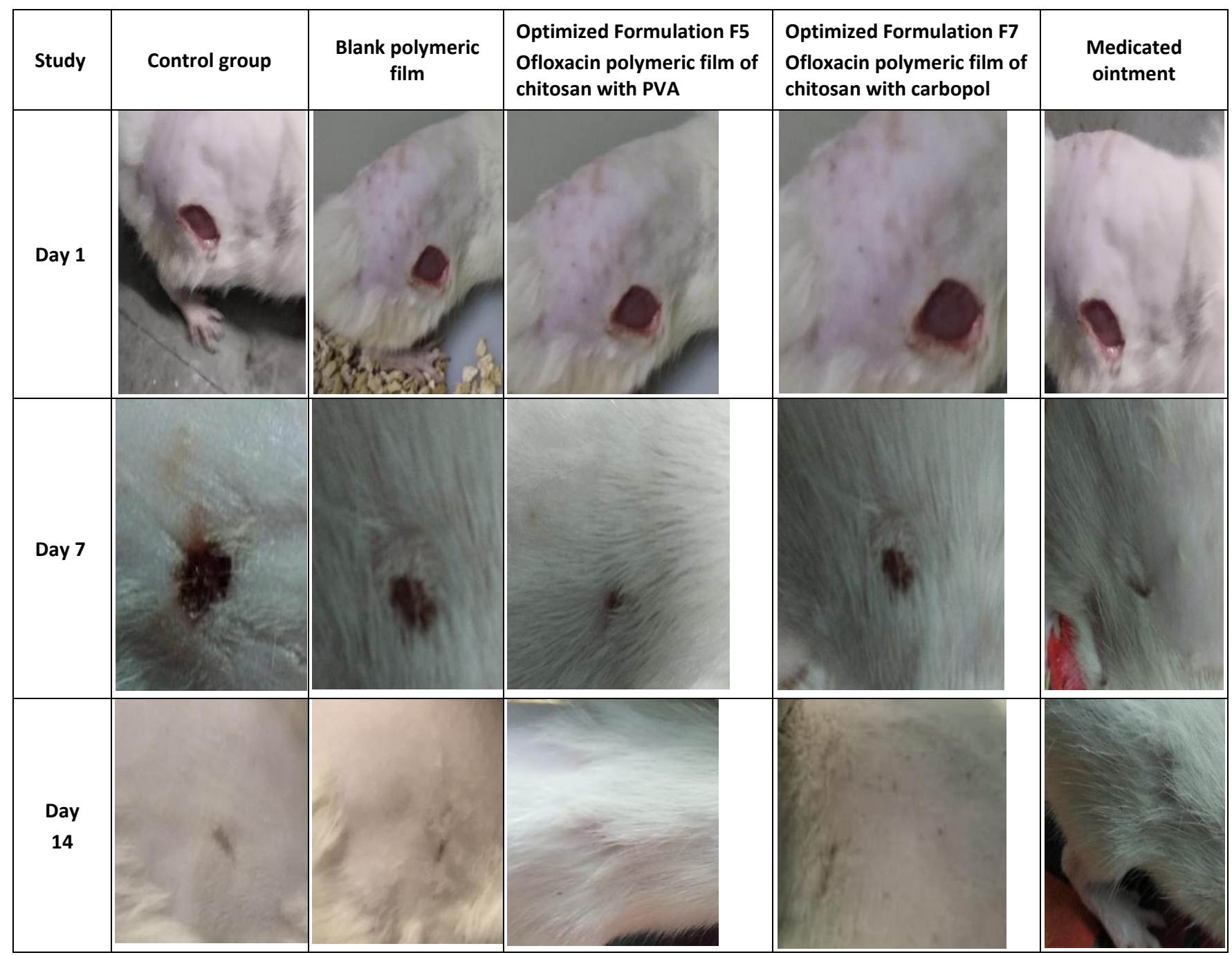

Figure 3: Progression of wound healing

\section{Animal Study}

Animal study was performed to evaluate wound healing activity of the films. Wound contracture was measured by the formula as mentioned earlier. The wound area was measured on day 1, 7 and 14. The developed optimized medicated films showed similar wound contracture as compared to the marketed preparation. The placebo film also showed considerable wound contracture, which shows that chitosan has wound healing activity. The 
wound area was measured using tracing method in which the wound area was traced on a tracing paper. This tracing was transferred to the graph paper. The squares under the traced area were calculated to determine the wound area. Then the wound contracture was measured in percentage. The wound contracture of the groups of animal study is mentioned in Table 6 and Fig. 3.

Table 6: Wound Contracture of the Groups of Animal Study

\begin{tabular}{|c|c|}
\hline Groups & \% Wound contracture \\
\hline Group 1 & $82.89 \pm 2.6$ \\
\hline Group 2 & $87.27 \pm 2.7$ \\
\hline Group 3 & $97.17 \pm 1.03$ \\
\hline Group 4 & $93.33 \pm 0.93$ \\
\hline
\end{tabular}

\section{CONCLUSION}

Composite films of chitosan containing Ofloxacin were developed with the aim to achieve sustained drug delivery of Ofloxacin at the site of application for wound dressing. Ofloxacin is an effective antibacterial agent acting against both Gram positive and Gram negative bacteria. The films developed were thin, flexible and stable during the period studied. In vitro release study showed that films of chitosan with PVA and chitosan with carbopol 940 have sustained release to a greater extent. The release was easily controlled with initial burst release followed by sustained released and was very favourable for an antibiotic release since Ofloxacin concentration was several times above typical MIC of several microorganisms. The films showed good antibacterial activity by agar diffusion method. In vivo wound healing study showed greater percent contraction than the Control in one week. Thus Ofloxacin loaded chitosan polymeric films can serve as a promising and superior alternative for wound management.

Acknowledgements: The authors thank Management of Oriental College of Pharmacy for extending their support and co-operation throughout the research work. We would also like to thank Bharat Serums and Vaccines for providing us with animals required for the study.

\section{REFERENCES}

1. Jayakumar $R$, Prabaharan $M$, Sudheesh Kumar $P$, Nair $\mathrm{S}$, Tamura $\mathrm{H}$. Biomaterials based on chitin and chitosan in wound dressing applications. Biotechnol. Adv. 29, 2011, 322-337.

2. Xiao B, Wan Y, Maoqi Zhao, Yiqun Liu. Preparation and characterization of antimicrobial chitosan- $\mathrm{N}$-arginine with different degrees of substitution. Carbohydr. Polym. 83, 2011, 144-150.

3. Mayet N, Choonara Y, Pradeep K, Lomas T, Charu T, Lisa T, Viness P. Comprehensive Review of Advanced Biopolymeric Wound Healing Systems. J. Pharm. Sci. 103, 2014, 22112230.

4. Dunn R, Ottenbrite R. Polymeric Drugs and Drug Delivery Systems. Ed.; American Chemical Society, ACS Symp.: Washington, DC, Series 469. 1991. 251.

5. Nokaly E. Polymeric Delivery Systems, Properties and Applications; American Chemical Society, Symp.: Washington, DC, Series, 520, 1993, 18-41.

6. Shakeel A, Saiqa I. Chitosan Based Scaffolds and Their Application in Wound Healing, Achievements in the Life Sciences. 10 (1), 2016, 27-37.

7. Eduardo P, Tasia D, Marco N, Aldo M, Marconi G, Fernanda R. Mechanical Properties and Release Studies of Chitosan Films Impregnated with Silver Sulfadiazine, Journal of Applied Polymer Science. 102, 2006, 3462-3470.

8. Maryam K, Abdolghani A, Basireh N, Sara B. Chitosan and Polyvinyl Alcohol Composite Films containing Nitrofurazone: Preparation and Evaluation, Iranian Journal of Basic Medical Sciences, 17(1), 2014, 14-20.

9. Neslihan O, Nesrin H., Mehmet O, Şule A, Ayşegül Y, Panoraia S, Erdal C. An Alternative Approach to Wound Healing Field; New Composite Films from Natural Polymers for Mupirocin Dermal Delivery, Saudi Pharmaceutical Journal, 27(5), 2019, 738-752.

10. Pai S, Gagangras S, Kulkarni S, Majumdar A. Potential of Ozonated Sesame Oil to Augment Wound Healing in Rats. Indian J. Pharm. Sci. 76 (1), 2014, 87-92.

Source of Support: None declared.

Conflict of Interest: None declared.

For any question relates to this article, please reach us at: editor@globalresearchonline.net

New manuscripts for publication can be submitted at: submit@globalresearchonline.net and submit_ijpsrr@rediffmail.com 